\title{
st \\ Tecnociência comercialmente orientada ou investigação multiestratégica?
}

Hugh LAGEY

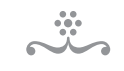

RESUMO

$\mathrm{O}$ modelo das interações entre as atividades científicas e os valores (M-CV) fornece ferramentas para criticar as atividades científicas atualmente predominantes nas instituições científicas e identificar algumas possibilidades alternativas de pesquisa que nessas instituições não estão recebendo o devido reconhecimento. Sobretudo, o M-CV ajuda-nos a identificar uma incoerência profunda na autointerpretação comum da tradição da ciência moderna e também a discernir que atualmente estão disponíveis duas alternativas coerentes e opostas - a "tecnociência comercialmente orientada" e a "pesquisa multiestratégica" -, capazes de eliminar essa incoerência e, ao mesmo tempo, de manter a continuidade do grande sucesso cognitivo da ciência moderna.

PALAVRaS-GhaVe • Tecnociência comercialmente orientada. Pesquisa multiestratégica.

Estratégias descontextualizadoras. Imparcialidade. Abrangência. Neutralidade. Progresso tecnológico. Justiça social. Sustentabilidade.

\section{INTRODUÇÃO}

O modelo das interações entre as atividades científicas e os valores (M-CV) ${ }^{\mathbf{1}}$ fornece ferramentas tanto para criticar as atividades científicas atualmente predominantes nas instituições científicas, quanto para identificar algumas possibilidades alternativas de pesquisa que não estão recebendo o devido reconhecimento nessas instituições. Neste artigo, argumentarei que - embora o grande sucesso cognitivo e prático da ciência moderna seja incontestável - a autointerpretação comum da tradição científica moderna é profundamente incoerente, isto é, a interpretação que afirma que a pesquisa científica é investigação empírica sistemática geralmente conduzida mediante o uso das estratégias descontextualizadoras (SDs) e autorregulada de acordo com os ideais da imparcialidade, neutralidade, abrangência e autonomia (cf. Lacey \& Mariconda, neste número, seção 3.2). A incoerência é derivada do fato de que a pesquisa, conduzida

1 Ver Lacey \& Mariconda (neste número). Neste artigo utilizo, sem maior elaboração, os conceitos, terminologia, simbolismo e siglas ali apresentadas em Apêndice com formulações padronizadas das principais ideias do M-CV e também traduções de alguns trechos de Lacey (2012a, 2014,b). 
em grande parte sob as SDs, não pode produzir resultados que se aproximariam (mesmo a longo prazo) aos ideais de neutralidade e abrangência, e cria em certas condições tensões com a imparcialidade (ver a seção1.4 adiante). Entretanto, argumentarei, também utilizando as ferramentas fornecidas por M-CV, que se pode manter a continuidade com os sucessos da ciência moderna por meio da adoção de uma ou outra entre duas interpretações coerentes:

(1) a tecnociência comercialmente orientada (TC), na qual a adoção das estratégias mantém relações de reforço mútuo com a perspectiva de valor do progresso tecnológico $\left\{\mathrm{V}_{\mathrm{PT}}\right\}$, interpretada a luz da perspectiva de valor do capital e do mercado $\left\{\mathrm{V}_{\mathrm{C \& M}}\right\}$;

(2) a pesquisa multiestratégica (P-MS), na qual a adoção de algumas estratégias mantém relações reforçadoras com a perspectiva de valor da justiça social, da democracia participativa e da sustentabilidade $\left\{\mathrm{V}_{\text {JSDPS }}\right\}$ (ver seção 4.1.1).

\section{OS HORIZONTES GARTESIANO E BACONIANO}

E O AUTOENTENDIMENTO DA TRADIÇÃO DA GIÊNGIA MODERNA

Primeiro será conveniente recapitular e desenvolver algumas das conclusões apresentadas em Lacey \& Mariconda (neste número).

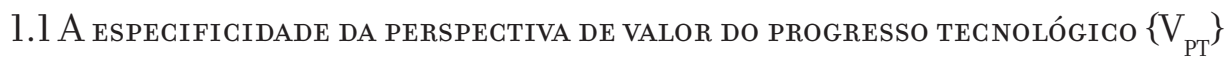

Existem relações de reforço mútuo entre a adoção de uma estratégia (S) em um projeto de pesquisa e a sustentação de uma perspectiva de valor $\{\mathrm{V}\}$ incorporada em práticas e instituições no mundo da vida: $\mathrm{S} \longrightarrow\{\mathrm{V}\}$ (cf. Lacey \& Mariconda, neste número, fig. 1). A sustentação de uma perspectiva de valor frequentemente contribui para explicar a adoção da estratégia, notavelmente $\left\{\mathrm{V}_{\mathrm{PT}}\right\}$ contribui para explicar a adoção quase exclusiva das estratégias descontextualizadoras SDs, ou seja, $\mathrm{SDs} \longleftrightarrow-\left\{\mathrm{V}_{\mathrm{PT}}\right\}$ (cf. Lacey \& Mariconda, neste número, fig. 3).

A sustentação de $\left\{\mathrm{V}_{\mathrm{PT}}\right\}$ deriva da convicção de que o controle ("a dominação da natureza" de Bacon) é a postura humana característica com relação aos objetos naturais. Ora, o exercício do controle de (alguns) objetos naturais - e, até certo grau, também o aumento das capacidades humanas de controle - é um valor para todas as \{V\}, desde que os seres humanos sejam, entre outras coisas, seres materiais com necessidades materiais. O que é específico para $\left\{\mathrm{V}_{\mathrm{PT}}\right\}$ é que o exercício do controle torna-se 
um valor social que não é subordinado de forma sistemática e geral a outros valores sociais. Em contraste, para algumas $\{V\}$, por exemplo, $\left\{\mathrm{V}_{\text {JSDPS }}\right\}$ (ver a seção 3.1), o valor do controle está subordinado a outros valores que são incorporados nas formas de vida que (a) reconhecem uma variedade de posturas humanas em relação à natureza, que inclui, além do controle, a preservação, a conservação, a restauração e os vários análogos de diálogo e de cooperação entre pessoas (ver a seção 4.1.1); e (b) contestam as relações sociais exigidas para o fomento da $\left\{\mathrm{V}_{\mathrm{PT}}\right\}$.

\subsection{NeUtralidade E AbrangÊNGia:}

A NEGESSIDADE DAS ESTRATÉGIAS SENSÍVEIS AO GONTEXTO

O registro histórico demonstra que as pesquisas conduzidas sob as SDs foram fecundas e versáteis (cf. Lacey \& Mariconda, neste número, seção 3.1); e podemos antecipar que isso continuará no futuro previsível. Além disso, ele confirma que muitas das tecnologias resultantes dessa pesquisa eram e continuam a ser valorizadas quase universalmente, mas não confirma que a pesquisa conduzida em grande parte sob as SDs poderia ser regulada efetivamente de acordo com os ideais de neutralidade e abrangência (cf. Lacey \& Mariconda, neste número, seção 3.2). Em relação à neutralidade, a pesquisa conduzida sob as SDs produz resultados que servem desproporcionalmente bem os interesses vinculados a $\left\{\mathrm{V}_{\mathrm{PT}}\right\}$; e, atualmente, $\left\{\mathrm{V}_{\mathrm{PT}}\right\}$ tende a ser interpretada em relação aos interesses que incorporam $\left\{\mathrm{V}_{\mathrm{C \& M}}\right\}$, frequentemente em detrimento de $\left\{\mathrm{V}_{\text {JSDPS }}\right\}$. Com respeito à abrangência, as SDs bastam para investigar a estrutura subjacente de todos os fenômenos, processos e interações de seus componentes, e leis que os governam (as EPILs dos fenômenos), bem como para a pesquisa que visa a geração de inovações tecnocientíficas, mas não são suficientes para investigar todos os aspectos de todos os fenômenos no mundo da vida. Para investigar adequadamente, por exemplo, os agroecossistemas sustentáveis, os riscos e as alternativas às inovações tecnocientíficas e também a agência humana e a história social, é preciso utilizar, além de uma variedade das SDs, algumas estratégias não redutíveis às SDs, isto é, algumas estratégias sensíveis ao contexto (SCs). A adoção de várias das SCs mantém relações do reforço mútuo com a sustentação da $\left\{\mathrm{V}_{\text {JSDPS }}\right\}$. Sem a adoção de SCs para certas investigações, nem a neutralidade nem a abrangência poderiam funcionar como ideais reguladores das práticas científicas. O M-CV, que incorpora a concepção $\left[\mathrm{PS}_{1}\right]$ da pesquisa científica (cf. Lacey \& Mariconda, neste número, seção 3), permite a adoção, além da variedade das SDs comprovadamente fecundas, daquelas SCs que se espera que a longo prazo provem a sua fecundidade em gerar teorias que se tornem aceitas de acordo com a imparcialidade (ver a seção 4.1). 
A adoção das SCs para investigar certos fenômenos não implica a rejeição ou subestimação do papel essencial das SDs na pesquisa científica. O M-CV reconhece que as SDs são indispensáveis e ubíquas: (a) elas estão bem adaptadas para a investigação de muitos domínios de fenômenos e das EPILs dos fenômenos (pois todos os fenômenos têm aspectos relacionados a suas EPILs); (b) muitas aplicações dos resultados da pesquisa-SD (isto é, pesquisa conduzida sob as SDs) têm valor social quase universal; e será muito difícil tentar resolver problemas, tais como o da mudança climática e aqueles ligados à energia, sem a invenção e introdução de novas aplicações tecnológicas do conhecimento obtido na pesquisa-SD; (c) a pesquisa-SG (isto é, pesquisa conduzida sob as SCs) frequentemente utiliza (e precisa utilizar) conhecimento obtido sob as SDs, na agroecologia, por exemplo, o conhecimento dos componentes minerais, das bactérias, dos solos etc. (cf. Lacey, no prelo a). Porém, nada disso implica que se pode reduzir a metodologia científica ao uso exclusivo das SDs, nem tampouco fornece uma boa razão para manter a concepção de pesquisa científica $\left[\mathrm{PS}_{2}\right]$ (cf. Lacey \& Mariconda, neste número, seção 3.2), que prioriza as SDs até ao ponto da exclusividade.

Entretanto, a ideia de que o uso das SDs faz parte da definição da metodologia científica dominou a consciência da tradição científica moderna e continua, em geral, dominando sem encontrar muito desafio nas instituições científicas contemporâneas. Isso explica, em parte, o fato de que atualmente a grande maioria dos cientistas atribui prioridade a questões que podem ser bem tratadas sob as SDs e que (direta ou indiretamente) têm a ver com as inovações tecnocientíficas e sua eficácia, e não concedem muita (ou concedem muito pouca) prioridade às questões (sobre riscos, benefícios e alternativas) que dizem respeito à legitimidade da implementação das inovações.

\subsection{O PAPEL DA "GIÊNGIA BÁSICA"}

Tradicionalmente $\left[\mathrm{PS}_{2}\right]$ foi interpretada à luz dos dois seguintes horizontes: o cartesiano, de obter conhecimento compreensivo dos fenômenos e das EPILs do mundo (cf. Lacey, 2014,b), e o baconiano, da expansão das capacidades humanas no exercício do controle dos objetos naturais, ou seja, na expansão das capacidades humanas de fazer, fabricar, observar (medir), inovar, intervir e, assim, fortalecer $\left\{\mathrm{V}_{\mathrm{PT}}\right\}$ no mundo da vida, interpretado em termos do ideal da neutralidade. Mariconda (2014) documenta que os porta-vozes da ciência moderna, enquanto mantinham os seus laços com o ideal da abrangência, sempre se interessaram na expansão das capacidades humanas de controlar os objetos naturais e na utilização dessas capacidades na vida prática.

Essa interpretação atribui à "ciência básica" (empreendida sob as SDs) a capacidade de possibilitar, simultaneamente, tanto o crescimento de nosso entendimento do mundo da vida quanto a transformação desse mundo para melhorar progressiva- 
mente a vida humana; e assim atribui à ciência básica a função de fazer os dois horizontes sempre mais visíveis no mundo da vida, sem que um deles venha a obscurecer o outro. Por um lado, a ciência básica tornaria o horizonte cartesiano mais visível. Ela envolve o empreendimento da pesquisa - sem qualquer preocupação de que seus resultados tenham aplicação prática - que aproveita a versatilidade das SDs para obter cada vez mais entendimento das EPILs dos fenômenos do mundo e, a partir disso, entendimento de uma variedade crescente de fenômenos do mundo da vida. Em parte por causa disso, atribui-se valor intrínseco à ciência básica e também porque ela se tornou uma contribuição cultural valorizada na modernidade. A ciência básica foi considerada como uma prática que introduziu um novo estilo de representar o mundo e que ofereceu possibilidades exemplares para o florescimento de seus participantes, devido ao cultivo, até novos níveis de perfeição, de características distintivamente humanas, tais como a criatividade matemática e teórica, a inteligência computacional e a inventividade experimental, tecnológica e prática. Por outro lado, à luz das relações de reforço mútuo entre a adoção das SDs e a sustentação da $\left\{\mathrm{V}_{\mathrm{PT}}\right\}$, a pesquisa básica produz conhecimento que frequentemente (às vezes a longo prazo) informa aplicações que fortalecem a manifestação de $\left\{\mathrm{V}_{\mathrm{PT}}\right\}$, que se diz que contribuem para melhorar a vida humana e, assim, para tornar o horizonte baconiano mais visível. Por conseguinte, a ciência básica tem valor não só intrínseco, mas também instrumental. Os cientistas individuais, especialmente os que fazem contribuições importantes, tendem a enfatizar o valor intrínseco, mas, para as instituições científicas, o valor instrumental geralmente tende a ter maior saliência.

A ciência básica tem valor provavelmente para todas as perspectivas de valor viáveis no mundo da vida atual. Entretanto, permanecem abertas questões acerca de como o seu empreendimento pode ser regulado de acordo com os ideais de abrangência e neutralidade. Embora a fecundidade e a versatilidade das SDs sejam incontestáveis, elas não são suficientes para confirmar que todos os fenômenos possam ser tratados adequadamente na pesquisa-SD e, portanto, que a abrangência possa funcionar como um ideal regulador para a ciência básica. Sem recurso à metafísica materialista (à tese de que todos os fenômenos são explicáveis em termos das EPILs) não se pode defender a reivindicação de que não há fenômeno (atual e futuro) que caia fora do alcance das SDs (cf. Lacey \& Mariconda, neste número, seção 3.2). Além disso, para defender que a ciência básica poderia ser regulada pelo ideal da neutralidade, seria necessário recorrer a vários pressupostos de $\left\{\mathrm{V}_{\mathrm{PT}}\right\}, \mathrm{P}-\left\{\mathrm{V}_{\mathrm{PT}}\right\}$ (cf. Lacey \& Mariconda, neste número, seção 3.4), especialmente ao pressuposto de que a adoção das SDs fornece a chave para a transformação do mundo a serviço dos seres humanos em geral e ao pressuposto de que a $\left\{\mathrm{V}_{\mathrm{PT}}\right\}$ é efetivamente um componente de qualquer perspectiva de valor viável atualmente. Mas a investigação desses pressupostos requer o uso de algumas SCs. 


\section{A AUtointerpretaÇÃo GOMUM DA TRAdiçÃo Gientífica MOderna}

Pode-se sumariar a autointerpretação comum da tradição científica moderna, aquela que atribui à ciência básica a função de assegurar a visibilidade dos dois horizontes, no esquema:

[1] Ciência moderna = SDs $+\mathrm{A}\{$ de fecundidade e versatilidade + metafísica materialista $\}+\mathrm{N}$ \{de controle como a postura humana característica para com a natureza $\}+\mathrm{I}+\ldots$,

onde $\mathrm{A}$ = abrangência; $\mathrm{N}$ = neutralidade; $\mathrm{I}$ = imparcialidade (que faz parte de $\left[\mathrm{PS}_{2}\right]$ ); “..." indica que existem outros itens no esquema - por exemplo, autonomia - que não discuto neste artigo.

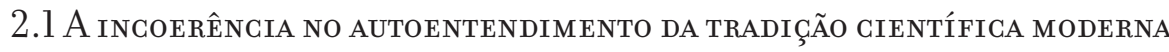

Considerações empíricas mostram que a combinação (SDs + A + N + I) não pode ser mantida coerentemente. Em primeiro lugar, a adoção quase exclusiva das SDs na pesquisa conduz a um conflito com a neutralidade. Os resultados obtidos na pesquisa-SD servem especialmente bem aos interesses vinculados a $\left\{\mathrm{V}_{\mathrm{PT}}\right\}$ e $\left\{\mathrm{V}_{\mathrm{C \& M}}\right\}$, frequentemente em detrimento de outras $\{\mathrm{V}\}$, por exemplo, $\left\{\mathrm{V}_{\text {JSDPS }}\right\}$ (ver a seção 1.2). Talvez isso não esteja em conflito com a neutralidade, se for uma condição necessária para a viabilidade das perspectivas de valor atuais que elas reflitam a proposta de que o controle é a postura humana característica em relação à natureza (ver a seção 1.1). Mas essa proposta não expressa um enunciado de fato; ela está inseparavelmente imbricada com a sustentação de $\left\{\mathrm{V}_{\mathrm{PT}}\right\}$. Em segundo lugar, existem fenômenos com certas características que podem ser investigados sob SCs propriamente escolhidas, e que agora não podem ser tratados adequadamente sob as SDs (ver a seção 1.2). A menos que se endosse a metafísica materialista, não há nenhuma razão para antecipar que, mesmo a longo prazo, as SDs poderiam manifestar versatilidade suficiente para tratá-los adequadamente e, portanto, para sustentar que o uso exclusivo das SDs poderia conduzir na direção da abrangência (cf. Lacey \& Mariconda, neste número, seção 3.2). Porém, dado que a metafísica materialista não é um resultado nem um pressuposto de condução da pesquisa sob as SDs (cf. Lacey, 2009), e que ela é inconsistente com os pressupostos de algumas $\{\mathrm{V}\}$ (por exemplo, aquelas que pressupõem que as categorias intencionais não podem ser reduzidas às categorias materialistas), o custo de vincular a abrangência àquela metafísica é o de produzir um conflito com a neutralidade enquanto ideal regulador. Em terceiro lugar, é preciso levar em conta os riscos das inovações tecnocien- 
TegnogiênGia Gomergialmente orientada ou inVestigaÇÃo multiestratégica?

tíficas entre os fenômenos cuja investigação adequada requer a adoção de algumas SCs. Entretanto, nas instituições em que $\left\{\mathrm{V}_{\mathrm{PT}}\right\}$ é sustentada, os efeitos colaterais das inovações no mundo da vida permanecem subinvestigados e a importância das SCs não é reconhecida. As análises de risco padrão (ver a seção 5.1) são conduzidas sob as SDs, mas estas não podem tratar adequadamente de todos os riscos ocasionados no mundo da vida, especialmente os riscos a longo prazo e aqueles que têm mecanismos socioeconômicos. A reivindicação da suficiência das SDs para a pesquisa científica produz, portanto, ameaças à imparcialidade. Além disso, uma vez que esses riscos têm grande sig-

nificado para aqueles que sustentam a $\left\{\mathrm{V}_{\text {JSDPS }}\right\}$, as limitações das análises de risco padrão confirmam a tensão entre a pesquisa-SD e o papel regulador da neutralidade.

\section{OpÇÕES ATUAIS PARA MANTER A CONTINUIDADE DA TRADIÇÃO GIENTÍFICA MODERNA}

À luz da incoerência envolvida na combinação (SDs + A + N + I), quais seriam as opções disponíveis para reinterpretar e reorientar a tradição científica de maneira a evitar a incoerência e, ao mesmo tempo, manter a continuidade com as contribuições positivas e características importantes da tradição? Existe uma opção que conduza à recuperação da imparcialidade, neutralidade e abrangência como ideais reguladores?

Identificarei duas opções, que denomino "tecnociência comercialmente orientada" (TC) e "pesquisa multiestratégica" (P-MS). As instituições científicas atuais dão ênfase impressionante a TC, e isso, como veremos, conduz ao enfraquecimento dos três ideais. Por outro lado, faz parte do objetivo da P-MS fortalecer o papel dos ideais. Porém, parece que sua viabilidade e seu desenvolvimento a longo prazo dependem, até certo ponto, de condições sociais e institucionais que poderiam tornar-se disponíveis apenas se as instituições cientificas fossem profundamente reorientadas (ver as seções $3.3 ; 6$ ).

\subsection{TEGNOGî̂NGIA GOMERGIALMENTE ORIENTADA}

De acordo com a concepção $\left[\mathrm{PS}_{2}\right]$ da pesquisa científica (cf. Lacey \& Mariconda, neste número, seção 3.2), a TC limita a investigação científica ao uso de SDs, e os seus resultados, no momento da aplicação $\left(\mathrm{M}_{5}\right)$, servem especialmente bem os interesses que incorporam $\left\{\mathrm{V}_{\mathrm{PT}}\right\}$. TC aproveita a contribuição tecnológica da pesquisa e para a pesquisa, e aumenta direta ou indiretamente os poderes humanos de intervir na natureza e ganhar mais controle sobre os objetos naturais (cf. Lacey, 2012a). Na TC, a tecnologia mais avançada, ela mesma informada pelo conhecimento obtido sob SDs, é usada para 
produzir instrumentos e novos objetos e estruturas que nos capacitam a ganhar conhecimento de objetos, eventos e estados de coisas em domínios novos, especialmente conhecimento (que contribui para fortalecer $\left\{\mathrm{V}_{\mathrm{PT}}\right\}$ ) do que podemos fazer e construir. Isso acontece de acordo com o fim de contribuir para a inovação prática, industrial e médica, e para o crescimento econômico e a competição, sendo reforçado pelo fato de que, nas instituições científicas que fornecem as condições para empreender a pesquisa na $\mathrm{TC},\left\{\mathrm{V}_{\mathrm{PT}}\right\}$ tende a ser interpretada em termos de sua contribuição ao fortalecimento de $\left\{\mathrm{V}_{\mathrm{C \& M}}\right\}$. Essa interpretação, por sua vez, leva à tendência de determinar as prioridades para a pesquisa por referência ao objetivo de obter inovações tecnocientíficas que possam fortalecer $\left\{\mathrm{V}_{\mathrm{C \& M}}\right\}$, e também, ao mesmo tempo, valores a ela relacionados, tais como liberdade individual, saúde pessoal e segurança nacional. $\mathrm{O}$ apelo proporcionado pela TC deriva das relações de reforço mútuo entre a adoção das SDs e a sustentação da $\left\{\mathrm{V}_{\mathrm{PT}}\right\}$, e do fato de que as instituições que incorporam $\left\{\mathrm{V}_{\mathrm{C \& M}}\right\}$ são os principais portadores contemporâneos de $\left\{\mathrm{V}_{\mathrm{PT}}\right\}$ e, além disso, $\left\{\mathrm{V}_{\mathrm{PT}}\right\}$ e $\left\{\mathrm{V}_{\mathrm{C \& M}}\right\}$ são amplamente sustentadas e altamente incorporadas nas instituições hegemônicas (comerciais, governamentais, políticas, educacionais etc.) do mundo da vida atual.

Ademais, o objetivo de servir aos interesses que incorporam $\left\{\mathrm{V}_{\mathrm{PT}}\right\}$ e $\left\{\mathrm{V}_{\mathrm{C \& M}}\right\}$ fornece impulso adicional para privilegiar as SDs e não levar a sério a proposta de utilização das SCs; de modo que, portanto, a pesquisa estimulada por esse objetivo não pode ser regulada pelo ideal da abrangência. A tecnociência é pesquisa conduzida sob SDs; os objetos investigados, as possibilidades exploradas e alguns dos métodos específicos usados são de interesse especial para aqueles que sustentam $\left\{\mathrm{V}_{\text {C\&M }}\right\}$, de modo que grande parte do financiamento para a pesquisa tecnocientífica está motivada pelas ligações entre a pesquisa científica, a inovação tecnocientífica, a obtenção de vantagens econômicas e o crescimento econômico (cf. Lacey, 2012a). Para a TC, a neutralidade não é uma preocupação de primeira ordem. Diz-se, por vezes, que em virtude do progresso tecnológico e econômico servir ao bem-estar de todo mundo, a TC satisfaz a neutralidade; mas essa reivindicação não poderia ser confirmada empiricamente sob as SDs. Efetivamente, isso significa que a neutralidade não funciona como um ideal regulador na TC.

O horizonte baconiano torna-se mais visível na TC, enquanto o cartesiano é obscurecido. Isso não significa que as instituições da TC dispensem a ciência básica. Entretanto, embora alguns cientistas individuais continuem motivados pela ideia do valor intrínseco da ciência básica, há uma tendência nas instituições de tratar a ciência básica de maneira instrumental e de proporcionar algum apoio quando se antecipa que ela conduzirá a resultados potencialmente úteis para o empreendimento dos programas de pesquisa da TC. Para conduzir pesquisa que visa obter inovações com potencial de utilização prática imediata, frequentemente o input da teoria básica é exigido e 
também a disponibilidade de instrumentos que tornam possível a manipulação dos materiais. A pesquisa que produziu os transgênicos, por exemplo, exigiu o input do conhecimento já obtido (na ciência básica) das estruturas moleculares de genomas; as curas prometidas pela pesquisa conduzida com as células-tronco dependem do conhecimento básico do desenvolvimento dessas células; a nanotecnologia tornou-se possível depois da construção dos instrumentos que permitem a manipulação de moléculas individuais. Além disso, atualmente alguns produtos/inovações tecnocientíficos - instrumentos de medida, substitutos automáticos para observação e intervenção, aparelhos experimentais e computadores com grande capacidade de análise de dados e de simulação de processos - são exigidos para conduzir a ciência básica. Do que se segue que a inovação tecnocientífica pode ser um produto colateral da criação e uma implementação das condições necessárias para conduzir a pesquisa básica. Por conseguinte, apesar de seus objetivos serem muito distantes dos interesses imediatos do mercado, continuam a ser conduzidas pesquisas que buscam desenvolvimentos teóricos ou a construção de novos instrumentos, algumas vezes, porque certos tipos de produtos não podem ser desenvolvidos sem o seu input, mas, outras vezes, apenas por causa da esperança de que, mais cedo ou mais tarde, ela conduzirá ao retorno do investimento ("pay off") feito nessa pesquisa. De qualquer modo, o valor da pesquisa básica deriva principalmente de sua contribuição ao fortalecimento da $\left\{\mathrm{V}_{\mathrm{PT}}\right\}$ e da $\left\{\mathrm{V}_{\mathrm{C \& M}}\right\}$ (cf. Lacey, 2012a) e, como um indício disso, a obtenção de patentes tornou-se um critério para a avaliação da produtividade científica em muitas instituições científicas e universidades.

Para a TC, o esquema [1] deve ser substituído por:

[2a] TC $=\operatorname{SDs}\left\{(\right.$ adoção das SDs $)<$ (sustentação de $\left.\mathrm{V}_{\mathrm{PT}}\right) \longleftrightarrow$ (sustentação de $\left.\left.\mathrm{V}_{\mathrm{C} \& \mathrm{M}}\right)\right\}+\mathrm{I}+\ldots .$.

\subsection{Pesquisa multiestratégica}

A P-MS incorpora o pluralismo estratégico (cf. Lacey \& Mariconda, neste número, seção 4). Reconhece que as SDs têm um papel de grande importância na pesquisa científica e que a prática da ciência básica tem valor intrínseco, mas, ao mesmo tempo, utiliza algumas SCs para investigar fenômenos que caem fora do alcance da pesquisa-SD e que são importantes para as perspectivas de valor que contestam a $\left\{\mathrm{V}_{\mathrm{C \& M}}\right\}$. Da mesma maneira que a adoção das SDs tem relações de reforço mútuo com sustentação de $\left\{\mathrm{V}_{\mathrm{PT}}\right\}$, geralmente a adoção das SCs terá relações desse tipo com a sustentação de perspectivas de valor particulares, frequentemente a $\left\{\mathrm{V}_{\mathrm{JSDPS}}\right\}$. 
A P-MS não se defronta com as mesmas dificuldades que a TC, com respeito ao ideal regulador de abrangência; pois, em vez do recurso à metafísica materialista da tradição científica, utiliza um pluralismo estratégico amplo (SDs + SCs) em uma tentativa de tratar dos fenômenos não são adequadamente tratados pelas SDs. Além disso, pode-se obter na pesquisa-SC resultados que serviriam aos interesses das perspectivas de valor que contestam $\left\{\mathrm{V}_{\mathrm{PT}}\right\}$ e $\left\{\mathrm{V}_{\mathrm{C} \& \mathrm{M}}\right\}$. Assim, de modo diferente de TC, P-MS possibilita que a neutralidade - a inclusividade e equitatividade (cf. Lacey, 2013) - funcione como um ideal regulador.

Então, o seguinte esquema substituirá [1]:

[2/b] $\mathrm{P}-\mathrm{MS}=[\mathrm{SDs}+\mathrm{SCs}]\{$ papel para muitas perspectivas de valor $\}+\mathrm{A}\{\mathrm{do}$ pluralismo estratégico $\}+\mathrm{N}$ \{inclusividade e equitatividade $\}+\mathrm{I}+\ldots$.

\subsection{COMPARAÇÃo ENTRE AS DUAS OPÇÕES}

Indiquei (ver a seção 2.1) que não é possível manter juntos todos os itens do esquema $(\mathrm{SDs}+\mathrm{A}+\mathrm{N}+\mathrm{I}+\ldots)$. Tanto TC como P-MS preservam alguns itens desse esquema e excluem outros, mas preservam e excluem itens diferentes; e ambas aceitam todo conhecimento científico estabelecido de acordo com a imparcialidade a partir da pesquisa-SD. Nesse sentido as duas opções mantêm contato forte com a tradição científica.

Para TC, a ideia de que as SDs são parte integral da definição da metodologia científica é fortalecida. TG retém a utilização quase exclusiva das SDs, de maneira que relaciona a ciência explicitamente ao fortalecimento de interesses informados por $\left\{\mathrm{V}_{\mathrm{PT}}\right\}$ e $\left\{\mathrm{V}_{\mathrm{C} \& \mathrm{M}}\right\}$, mas ao preço de que a abrangência e a neutralidade não podem funcionar como ideais reguladores plausíveis.

P-MS rejeita a utilização quase exclusiva das SDs, mas não a utilização das SDs para tratar de certos tipos de fenômenos e as EPILs dos fenômenos, e permite que a investigação seja conduzida sob as SCs que têm relações de reforço mútuo com as perspectivas de valor, tais como $\left\{\mathrm{V}_{\mathrm{JSDPS}}\right\}$, que estão em conflito com $\left\{\mathrm{V}_{\mathrm{PT}}\right\}$ e $\left\{\mathrm{V}_{\mathrm{C} \& \mathrm{M}}\right\}$. P-MS mantém o papel regulador dos ideais de abrangência e neutralidade, embora provisoriamente, porque deixa aberta a possibilidade de que os desenvolvimentos da pesquisa e as formas de institucionalização da ciência mostrem limites ao papel dos ideais. Se a abrangência e a neutralidade podem ou não efetivamente funcionar como ideais reguladores para a pesquisa científica é uma questão para resolução a partir de pesquisa conduzida a longo prazo que utilize efetivamente uma variedade de estratégias (tanto SCs quanto SDs). Para P-MS, o empreendimento da pesquisa sob um tipo particular de estratégia - não só as SDs, mas também as SCs (ver a seção 4.1) - frequentemente obtém 
a sua justificativa (em parte) da sustentação de uma perspectiva de valor particular. Mas, por meio de incorporação do pluralismo estratégico (SDs + SCs), P-MS evita a ligação da ciência em geral a uma perspectiva de valor particular. O ideal de neutralidade exige que, para cada perspectiva de valor viável nas sociedades contemporâneas, alguma pesquisa seja conduzida sob estratégias que têm com ela relações de reforço mútuo. Mas é uma questão prática da pesquisa descobrir se, para uma perspectiva de valor particular, há uma estratégia relevante, e se a pesquisa conduzida sob ela é fecunda. Os prospectos a longo prazo de manter o ideal da neutralidade dependem dos resultados da pesquisa. A curto prazo, o compromisso com a neutralidade requer a exploração ativa da possibilidade de que, para cada uma daquelas perspectivas de valor, exista pesquisa fecunda que poderia servi-la. É nesse sentido que P-MS incorpora o ideal da neutralidade. Segue-se que a adesão à democracia participativa ajusta-se bem a essa reinterpretação da tradição científica. Por conseguinte, a abertura de espaço nas instituições científicas para permitir pesquisa sob SCs poderia fortalecer tanto a democracia na sociedade como a neutralidade na ciência.

Diz-se, frequentemente, que a ciência transformou-se atualmente em tecnociência e que não seria realista pensar que haja uma opção alternativa à TC. De tal ponto de vista, P-MS deve ser considerada uma opção só no sentido lógico ou conceitual. Isso porque, à luz da hegemonia de TC nas instituições científicas, baseada na sua relação $\operatorname{com}\left\{\mathrm{V}_{\mathrm{PT}}\right\}$ e $\left\{\mathrm{V}_{\mathrm{C} \& \mathrm{M}}\right\}$, P-MS não poderia obter as condições materiais, sociais e institucionais necessárias para o seu empreendimento. Porém, é importante não reduzir a ciência a suas formas institucionalizadas atuais (cf. Lacey \& Mariconda, neste número, introdução). Essas formas constituem apenas um estágio da trajetória da tradição científica, que pelo menos até recentemente, de acordo com as declarações de seus porta-vozes, podem (e devem) ser reguladas para refletir os ideais de imparcialidade, neutralidade, abrangência e autonomia. O recurso a esses ideais pode gerar a motivação para tentativas de reinstitucionalizar a ciência. Se for possível reinstitucionalizar a ciência e estabelecer as condições exigidas para empreender efetivamente P-MS, a pesquisa científica poderia ter concordância mais fiel com alguns dos ideais. $\mathrm{O}$ argumento de que essa não é uma opção realista representa uma postura política que pressupõe que os poderes econômicos e políticos atualmente predominantes serão capazes de enfrentar quaisquer desafios que visem a incorporação social de valores opostos a $\left\{\mathrm{V}_{\mathrm{PT}}\right\}$ e $\left\{\mathrm{V}_{\mathrm{C \& M}}\right\}$. Os esforços de reinstitucionalização da ciência de modo a fornecer as condições do empreendimento efetivo de P-MS terão objetivos compartilhados com os movimentos sociais que adotam postura política diferente, a qual incorpora $\left\{\mathrm{V}_{\mathrm{SJDPS}}\right\}$ (cf. Lacey, 2008b; 2012b; 2014a). 


\section{Implicações da PeSQuisa multiestratéGica}

Quais seriam as implicações do empreendimento efetivo da P-MS? Neste momento, pode-se identificar um grande alcance de fenômenos que não podem ser investigados sob as SDs atualmente disponíveis, inclusive muitos fenômenos que são pertinentes às práticas que incorporam várias das $\{\mathrm{V}\}$ opostas a $\left\{\mathrm{V}_{\mathrm{PT}}\right\}$ e $\left\{\mathrm{V}_{\mathrm{C \& M}}\right\}$. Porém, não é possível investigar todos os fenômenos (em parte devido a limites nos recursos e falta de pesquisadores treinados); é sempre necessário priorizar os fenômenos para a pesquisa e, dependendo das características deles, especificar as estratégias que devem ser adotadas; o que dá origem a muitas questões. Aqui discutirei duas delas:

(1) Quais são as SCs que devem ser adotadas e desenvolvidas com prioridade?

(2) Que tipo de postura crítica para com as prioridades, práticas e inovações da TC seria engendrada pela adoção da P-MS ?

\subsection{O PROGRAMA POSITIVO DA PESQUISA MULTIESTRATÉGICA}

No cerne do programa positivo da P-MS está o desenvolvimento de pesquisa que utilize as SCs (frequentemente junto com as SDs) com o fim de investigar aqueles fenômenos e reivindicações que não possam ser adequadamente investigados por meio unicamente das SDs, e que produza resultados que informem e fortaleçam práticas que incorporam as várias $\{\mathrm{V}\}$ que contestam $\left\{\mathrm{V}_{\mathrm{PT}}\right\}$ e $\left\{\mathrm{V}_{\mathrm{C \&}}\right\}$, por exemplo, $\left\{\mathrm{V}_{\text {JSDPS }}\right\}$. Tendo em vista o fato de que $\left\{\mathrm{V}_{\text {JSDPS }}\right\}$ já é incorporada em muitos movimentos sociais e nas aspirações de muitas pessoas no mundo todo, as estratégias que devem ser adotadas e desenvolvidas com prioridade incluirão aquelas cuja adoção tem relações de reforço mútuo com a sustentação de $\left\{\mathrm{V}_{\text {JSDPS }}\right\}$. Neste artigo, em vez de responder a questão geral (1) acima, vou pôr o foco nessas estratégias e considerar a seguinte questão:

Como deve ser conduzida a pesquisa científica (e por quem), com quais prioridades e utilizando quais estratégias, e como deve ser utilizado o conhecimento científico e as tecnologias desenvolvidas e administradas, de modo a assegurar que os direitos, o bem-estar e as condições para a participação construtiva numa sociedade democrática sejam fortalecidos para todo mundo em todo lugar, e que a natureza seja respeitada, que seus poderes regenerativos não sejam mais solapados e sejam restaurados sempre que possível? 
Essa questão fornece a direção para alguns esforços importantes que desafiam a hegemonia da TC (e de $\left\{\mathrm{V}_{\mathrm{PT}}\right\}$ e $\left.\left\{\mathrm{V}_{\mathrm{C \& M}}\right\}\right)$ nas instituições científicas contemporâneas. É irônico que uma questão, tão explicitamente comprometida com valores específicos, possa motivar pesquisa que também contribua para a reabilitação da neutralidade que é enfraquecida nessas instituições. ${ }^{2}$

Meu argumento em favor dos prospectos promissores do programa positivo da P-MS depende da reivindicação de que a pesquisa atualmente conduzida sob algumas SCs mostra-se fecunda, desafiando diretamente a justificação algumas vezes alegada para a hegemonia das SDs de que só a pesquisa conduzida sob as SDs pode ser fecunda. Para ilustrar e confirmar essa reivindicação, fiz amiúde recurso à pesquisa fecunda propiciada pelas estratégias usadas na agroecologia (por exemplo, Lacey, 2010: parte 2; no prelo a). Contudo, embora a agroecologia seja um caso exemplar, o argumento não depende apenas dela. Também em outras áreas conseguimos vislumbrar o empreendimento do programa positivo da P-MS, por exemplo, na tecnologia social (Garcia, 2014), na saúde pública (Lechopier, no prelo), na sustentabilidade e manejo florestal (Silva, no prelo), e nas pesquisas que adotam SCs que têm relações de reforço mútuo com valores feministas (cf. Lacey, 1999, cap. 9), tais como nas ciências do comportamento (cf. Longino, 2013) e na arqueologia (cf. Wylie, 2002; 2014). A agroecologia tem evidentemente um interesse especial para o modelo da interação em virtude do fato de que no Brasil a pesquisa agroecológica já está bem desenvolvida e mostra-se bastante fecunda (Nodari \& Guerra, no prelo), e que a adoção de suas estratégias tem relações de reforço mútuo com a sustentação de $\left\{\mathrm{V}_{\text {JSDPS }}\right\}$, uma perspectiva de valor amplamente sustentada por vários movimentos sociais e grupos de agricultores no Brasil. Enfatizo que meu argumento depende da existência de SCs fecundas. ${ }^{3}$

\footnotetext{
2 Essa questão, também levantada em Lacey (2008b; 2014a), é o princípio organizador de várias publicações do "Grupo de Pesquisa de Filosofia, História e Sociologia da Ciência e da Tecnologia" do IEA/USP, no âmbito do Projeto Temático Fapesp 2011/51614-3, "Gênese e significado da tecnociência: das relações entre ciência, tecnologia e sociedade" - os artigos, organizados por Pablo Mariconda e eu, publicados em Estudos Avançados (28, 82, 2014; 29, 83, 2015): sobre tecnologia social (Garcia, 2014), agroecologia (Lacey, no prelo a; Nodari \& Guerra, no prelo), saúde pública (Lechopier, no prelo), e sustentabilidade e manejo florestal (Silva, no prelo); e os artigos do special issue de Scientiae Studia $(12,2014)$, apresentados na sessão (organizada por Pablo Mariconda) do Congresso da Sociedade para a Filosofia da Tecnologia, "A tecnologia para a sustentabilidade, justiça social e o bem-estar de todos", em Lisboa, Portugal, 3-7 de julho de 2013 (Lacey, 2014,b). Ver, também, Lacey, 2014c.

3 Entretanto, fica fora do alcance deste artigo filosófico entrar nos detalhes teóricos e empíricos da pesquisa que utiliza as SCs. Para detalhes no caso da agroecologia, ver Nodari \& Guerra (no prelo) e as referências em Lacey (no prelo a).
} 


\subsubsection{A perspegtiva de VAlor da JUSTiÇa Social,} DEMOGRAGIA PARTICIPATIVA E SUSTENTABILIDADE \{VJSDPS\}

Farei aqui uma digressão no desenvolvimento do argumento para elaborar com algum detalhe a $\left\{\mathrm{V}_{\mathrm{JSDPS}}\right\}$. Isso permitirá que compreendamos melhor como a adoção das estratégias da agroecologia (e, também, da tecnologia social, da saúde pública e da sustentabilidade e manejo florestal) mantém relações de reforço mútuo com a sustentação de $\left\{\mathrm{V}_{\text {JSDPS }}\right\}$. Faz parte do ideal de florescimento ou bem-estar humano, pressuposto pela sustentação da $\left\{\mathrm{V}_{\text {JSDPS }}\right\}$, que todas as pessoas conduziriam suas vidas de modo que elas (e suas comunidades) pudessem cultivar e expressar os valores que elas mesmas sustentam e consideram constitutivas do bem-estar da vida. Esses valores estão intimamente vinculados à agência (ou seja, à capacidade de ação responsável) dos indivíduos e ao seu lugar em uma comunidade.

$\left\{\mathrm{V}_{\text {JSDPS }}\right\}$ refere-se a perspectivas de valor que incluem vários dos seguintes valores: solidariedade em equilíbrio com autonomia individual; bens sociais (por exemplo, segurança alimentar), considerados mais importantes do que a propriedade privada e os lucros; o bem-estar de todos é mais importante do que o mercado; o fortalecimento de uma pluralidade de valores em lugar da mercantilização; a emancipação humana em equilíbrio com a liberdade individual e a eficiência econômica; os direitos dos marginalizados e a equidade inter e intrageracional, considerados mais importantes do que os interesses do mercado; assumir responsabilidade para o futuro em vez da resignação frente aos projetos dos poderosos; a democracia enriquecida com mecanismos participativos e não limitada à democracia formal; equilíbrio apropriado entre direitos civis/políticos e sociais/econômicos/culturais; e sustentabilidade ambiental, vinculada às posturas humanas para com a natureza que envolvem a subordinação do controle ao respeito, manutenção/preservação/conservação/restauração/sustentação, adaptação, sintonização, cultivação, apreciação, contemplação da natureza (cf. Ramos, 2014).

$\left\{\mathrm{V}_{\text {JSDPS }}\right\}$ deve ser considerada como um tipo ideal. Podemos achar muitas variações nas articulações e manifestações dos valores na lista acima entre os movimentos sociais (por exemplo, aqueles que lutam por acesso à terra, pela soberania alimentar, pela moradia urbana, ou pelos direitos dos marginalizados), além de várias maneiras de construir a ordem de importância relativa dos valores. (De modo similar, $\left\{\mathrm{V}_{\mathrm{PT}}\right\}$ e $\left\{\mathrm{V}_{\mathrm{C \& M}}\right\}$ funcionam como tipos ideais no meu argumento.) 
Tegnogiêngia Comergialmente orientada ou investigaÇão multiestratégiga?

\subsection{A postura grítica engendrada pela P-MS para com a TC}

Aqueles que querem adotar a P-MS reconhecem as realizações positivas da TC e endossam o valor de muitas delas, e entendem que pesquisa conduzida sob as SDs retém um papel importante (mas não exclusivo) na P-MS. Eles adotam uma postura tanto crítica quanto perspicaz para com as prioridades, práticas e inovações da TC e para com o papel da inovação tecnocientífica no mundo da vida atual. Suas críticas geralmente têm a ver com o fato de que a pesquisa da TC não reflete a neutralidade como um ideal regulador, ou seja, que essa pesquisa geralmente não contribui com o patrimônio compartilhado da humanidade, mas serve especialmente bem interesses informados por $\left\{\mathrm{V}_{\mathrm{PT}}\right\}$ e $\left\{\mathrm{V}_{\mathrm{C \& M}}\right\}$, frequentemente ao custo dos interesses informados por $\left\{\mathrm{V}_{\text {JSDPS }}\right\}$. Apontaremos para dois aspectos da postura crítica.

\subsubsection{Consequências regorrentes da TC PARA AS INSTITUIÇÕES GIENTÍFICAS E OS GIENTISTAS PROFISSIONAIS}

Um aspecto da postura crítica deriva do fato de que a pesquisa da TC transformou-se em uma fonte produtiva de inovações eficazes que estão contribuindo para aumentar a incorporação de $\left\{\mathrm{V}_{\mathrm{PT}}\right\}$ e $\left\{\mathrm{V}_{\mathrm{C \& M}}\right\}$ nas instituições contemporâneas e, assim, fortalecer a trajetória social e econômica do capitalismo atual (neoliberalismo). As próprias instituições científicas do mainstream fazem parte integral dessa trajetória, e cada vez mais incorporam $\left\{\mathrm{V}_{\mathrm{PT}}\right\}$ e $\left\{\mathrm{V}_{\mathrm{C \& M}}\right\}$ mais profundamente. ${ }^{4}$ Isso gera consequências recorrentes para as instituições científicas e os cientistas profissionais (pertinentes a todas as etapas das atividades científicas, talvez especialmente às etapas $\mathrm{M}_{2}$ e $\mathrm{M}_{4}$ ); inclusive consequências a respeito das prioridades da pesquisa; das condições para o empreendimento da pesquisa; das fontes de financiamento da pesquisa e dos gastos das instituições científicas; da avaliação dos resultados da pesquisa e da produção dos cientistas; das oportunidades para emprego dos cientistas e avanço nas suas carreiras; do conteúdo do currículo da educação científica; da estrutura das instituições científicas e dos valores predominantemente incorporada nelas. Todas essas consequências tendem a gerar conflitos entre os interesses científicos e comerciais (cf. Oliveira, 2013; 2014; Domingues, 2014). Aqui, só quero apontar que essas consequências reforçam as dificuldades que os cientistas enfrentam nas instituições científicas atuais para conseguir espaço de modo a engajar-se em pesquisa SG. A atual direção social e econômica das formas neoliberais do capitalismo é um fato notável de nossa época histórica e configura-se, também, como um enorme obstáculo para o empreendimento do programa

4 Hoje em dia, o que eu denomino "tecnociência comercialmente orientada" é frequentemente denominado "ciência comercializada" ou "ciência no interesse privado" (cf. Oliveira, 2013). 
positivo da P-MS. Por um lado, a concepção de ciência da TC não admite um papel para as SCs na pesquisa "científica" e, por outro, dentro das estruturas e organização das instituições da ciência comercializada, geralmente não há nenhum reconhecimento dos êxitos da pesquisa SC.

\subsubsection{InVestigaçÃo Pertinente À LegitimaÇÃo do Uso DAS INOVAÇões DA TC}

O segundo aspecto diz respeito à inadequação das SDs tomadas isoladamente para investigar todos os assuntos relevantes à legitimidade das implementações de inovações no mundo da vida, inclusive os assuntos que têm grande importância para $\left\{\mathrm{V}_{\text {JSDPS }}\right\}$, por exemplo, riscos a longo prazo à saúde e ao ambiente, cujos mecanismos estão vinculados ao fato de que as inovações são mercadorias, objetos que incorporam os valores de $\left\{V_{\mathrm{PT}}\right\}$ e $\left\{V_{\text {C\&M }}\right\}$. A pesquisa que visa tratar esses assuntos requer a utilização de SCs. É muito importante lembrar - e a atitude cultivada pela P-MS estimula essa lembrança - que o sucesso impressionante da TC em produzir inovações que contribuem para o crescimento econômico, junto com o ímpeto implacável da trajetória do capitalismo atual, não são suficientes para justificar, para qualquer inovação eficaz, que a sua implementação no mundo da vida seja legítima, isto é, que as pessoas tenham direito (legal ou ético) de usá-la, ou que a inovação tenha usos valorizados. A sua legitimidade depende tanto de sua eficácia quanto dos benefícios esperados (e para quem), tanto de suas consequências prejudiciais, de seus riscos (e para quem), quanto da existência de alternativas "melhores" que sejam informadas pelos resultados da pesquisa SC. Por exemplo, a legitimidade do uso dos transgênicos depende da ausência de alternativas "melhores" tais como a agroecologia (cf. Lacey, 2006a; 2010, parte 2). A pesquisa SD geralmente será suficiente para estabelecer a eficácia. Entretanto, para justificar a legitimidade é necessário conduzir pesquisa sobre os outros assuntos mencionados e, geralmente, isso vai requerer a adoção de SCs apropriadas. Aqui é importante observar que quando os proponentes da TC reivindicam que a implementação de uma inovação no mundo da vida não ocasiona riscos (que não podem ser contidos com base em regulamentos apropriadamente designados) - uma vez que SCs não são utilizadas em suas pesquisas -, é provável que essas reivindicações sejam feitas em desacordo com a imparcialidade. Embora o ideal da imparcialidade seja geralmente importante na TC para as considerações de eficácia, no contexto das deliberações acerca da legitimidade, por vezes a imparcialidade torna-se subordinada aos interesses de $\left\{\mathrm{V}_{\mathrm{PT}}\right\}$ e $\left\{\mathrm{V}_{\mathrm{C \& M}}\right\}$. A crítica mais fundamental que se faz à TC a partir da $\mathrm{P}-\mathrm{MS}$ é a de que a TC carece dos recursos estratégicos para investigar adequadamente os assuntos pertinentes à legitimidade, ao custo de desacordo tanto com a neutralidade quanto com a imparcialidade (cf. Lacey, 2008b; 2014a). Desenvolverei as implicações disso detendo-me no assunto dos riscos. 
Tegnogiêngia Gomergialmente orientada ou investigaÇÃo multiestratégica?

\section{Riscos}

As inovações tecnocientíficas são amplamente procuradas por causa dos benefícios esperados por grupos com certos interesses; e esses grupos, dependendo dos valores refletidos nos seus interesses, podem ser mais ou menos inclusivos, com variação de caso para caso. Todo mundo reconhece, porém, que a introdução de uma inovação no mundo da vida será acompanhada por alguns riscos de causar danos a pessoas, a relações sociais e ao meio ambiente, e que sua introdução deve ser precedida e informada por pesquisas científicas relevantes sobre os riscos potenciais do uso da inovação no mundo da vida e os meios para regulá-los. Entretanto, há frequentemente desacordo acerca da natureza dos riscos, da sua extensão, seriedade ética, mecanismos, e acerca da capacidade de serem controlados com a ajuda de regulamentos bem planejados; por conseguinte, disputa-se acerca do tipo de pesquisa exigida para a investigação dos riscos e para informar o desenvolvimento dos regulamentos desenhados com o fim de eliminar ou minimizar a probabilidade da ocorrência de dano potencial.

A TC e a P-MS oferecem abordagens profundamente opostas para a identificação e investigação dos riscos.

\subsection{Riscos NA TC: o PRINGÍPIO DA LEGITIMIDAdE \\ DA INTRODUÇÃO DAS INOVAÇÕES TEGNOCIENTÍFICAS}

Atualmente, nas comissões de regulamentação, tende a ser aceita a interpretação da ciência fornecida pela TC e, assim, a limitação das estratégias utilizadas na pesquisa às SDs, inclusive nas pesquisas acerca dos riscos das inovações tecnocientíficas. A pesquisa utilizada nas análises de risco padrão (ARPs) utiliza somente SDs (cf. Mariconda, 2014); elas envolvem pesquisas sobre riscos diretos à saúde humana e ambiental (geralmente a curto prazo) ocasionados por mecanismos químicos, bioquímicos e físicos, de maneira que torna possível a determinação de suas relações quantitativas com outros fatores e a estimativa das probabilidades da sua ocorrência. Por conseguinte, as comissões instituídas geralmente requerem que, antes da introdução de uma inovação no mundo da vida, ela seja submetida a uma gama das ARPs (certificada como suficiente por especialistas "técnicos" relevantes). Então, com base nos resultados das ARPs, as comissões promulgam regulamentos apropriados para acompanhar a introdução da inovação, ou obrigam ao adiamento de sua introdução durante a condução de mais ARPs ou para dar tempo para a deliberação sobre os regulamentos relevantes, ou (algumas vezes) não permitem de forma alguma sua introdução. Para as comissões, depois de aplicar o teste das ARPs e de ter promulgados os regulamentos específicos e os mecanismos de seu policiamento, não sobram mais obstáculos para a introdução da 
inovação. Além disso, nesse contexto onde $\left\{\mathrm{V}_{\mathrm{PT}}\right\}$ e $\left\{\mathrm{V}_{\mathrm{C \& M}}\right\}$ são amplamente sustentadas e altamente incorporadas nas instituições econômicas/políticas/legais (hegemônicas), e os pressupostos de sua sustentação amplamente endossados, a responsabilidade legal de recompensar o dano causado pelo uso de uma inovação geralmente será considerada satisfeita, desde que a inovação tenha sido introduzida de acordo com as decisões das comissões.

Aplicar o teste das ARPs não significa ter o dever de introduzir a inovação. Em realidade, as pessoas e os corpos (corporações, investidores e governos que incorpo$\operatorname{ram}\left\{\mathrm{V}_{\mathrm{PT}}\right\}$ e $\left.\left\{\mathrm{V}_{\mathrm{C \& M}}\right\}\right)$ que têm interesse direto na introdução de uma inovação podem levar em consideração também outros tipos de riscos, por exemplo, o risco de não ganhar um retorno adequado em um investimento na inovação, ou o risco de prejuízo. Talvez em geral eles estejam mais preocupados com estes últimos riscos e, com o intuito de minimizá-los, desejam que as restrições legais para o uso das inovações sejam reduzidas ao mínimo, e que certamente não sejam mais fortes do que as propostas feitas pelas comissões com base nos testes ARPs realizados. Os interesses dessas pessoas e grupos serão geralmente bem servidos pelos procedimentos e pela constituição das comissões de regulamentação, cujas decisões aparecem como se fossem governadas por um princípio que denominarei o "princípio da legitimidade da introdução das inovações tecnocientíficas” (PLT). Esse princípio pode ser enunciado como segue:

Ceteris paribus, a menos que exista evidência científica forte, obtida em ARPs (certificadas, por especialistas relevantes, como suficiente), de que há riscos de prejuízo sério (que não podem ser administrados adequadamente por regulações e procedimentos para a sua execução), é legítimo implementar, sem demora, aplicações eficazes do conhecimento científico bem estabelecido na TG" (Lacey, 2008 b, p. 314).

Digo “como se”, pois, até onde sei, ninguém enunciou explicitamente um princípio tal como esse, mas as decisões de comissões regulamentares geralmente fornecem instâncias dele. PLT é um tipo de antítese do princípio de precaução (PP).

PLT é um componente integral da TG no sentido que, por meio da referência a PLT, podemos explicar aspectos importantes das atividades de aplicação (uso) do conhecimento obtido na TC. Então, faz sentido expandir o esquema [2a] (ver a seção 2):

\footnotetext{
[2A] TG $=\mathrm{SDs}\left\{(\right.$ adoção das $\mathrm{SDs})<$ (sustentação de $\left.\mathrm{V}_{\mathrm{PT}}\right) \longleftrightarrow$ (sustentação de $\left.\left.\mathrm{V}_{\mathrm{C \& M}}\right)\right\}+\mathrm{I}+\mathrm{PLT}+\ldots$
} 
Tegnogiêngia Gomergialmente orientada ou investigaÇão multiestratégica?

Entre os integrantes da TC, o PLT vem acompanhado das atitudes éticas: a pesquisa que visa o tratamento dos grandes problemas do mundo (prima facie) deve priorizar as "soluções" tecnocientíficas, por exemplo, o uso dos transgênicos para tratar da fome e da desnutrição; e considera-se eticamente irresponsável que se coloque em dúvida o potencial ou a legitimidade da pesquisa que possa conduzir a tais soluções (Lacey, 2008b).

\subsection{Riscos na Perspegtiva da P-MS: o PRincípio de PReGaução}

Afirmei acima que a P-MS engendra uma postura tanto crítica quanto perspicaz para com as prioridades, práticas e inovações da TG. Para o desenvolvimento da P-MS, continua sendo de grande importância não só alguma pesquisa-SD, complementada pela pesquisa-SC relevante, mas também a introdução de certas inovações tecnológicas, mas sem as decisões rápidas (permitidas pelo PLT) acerca da legitimidade de sua introdução. Os proponentes da P-MS reconhecem que, por um lado, algumas inovações, derivadas da pesquisa-SD, têm potencial de produzir grandes benefícios para muitas pessoas; e que, por outro lado, o seu uso (sob as condições socioeconômicas de seu uso atual) contribuiu significativamente para as grandes crises contemporâneas (de clima, poluição, ecossistemas devastados, violência armada, da própria economia). Desde que essas crises envolvem dimensões sociais e ecológicas planetárias, elas não poderiam ter sido evitadas a partir dos procedimentos de comissões regulamentares que incorporam o PLT, porque as ARPs não fazem uso das estratégias (SCs) necessárias para investigar seriamente os riscos envolvidos na implementação intensiva das inovações. (Quando os riscos e perigos se efetivam e transformam-se em catástrofes, em crises, que não podem ser ignoradas, por causa dos efeitos alarmantes e da necessidade urgente de intervenção de ação, as comissões utilizam algumas SCs.) Para investigar riscos desse tipo, as ARPs por si mesmas (mesmo uma gama bastante extensa delas) não se mostram adequadas. Portanto, tomar decisões informadas unicamente pelo PLT seria, com efeito, ignorar tais riscos.

Além disso, as consequências danosas e os riscos que lhes estão ligados, os quais resultam de agir informados pelo PLT, incluem o enfraquecimento (de várias maneiras) da incorporação de $\left\{\mathrm{V}_{\text {JSDPS }}\right\}$ no mundo da vida, por exemplo, no caso dos transgênicos, tornar cada vez mais difíceis as condições exigidas para a prática da agroecologia (Lacey, 2006a; 2010, parte 2; Mariconda, 2014). Essas consequências e riscos, assim como as crises, em virtude dos mecanismos de sua geração e do fato de que as probabilidades de sua ocorrência não podem ser computadas, ${ }^{5}$ caem fora do

5 A disciplina "técnica" da análise de risco por vezes define "risco" como algo que necessariamente pode ser investigado nas ARPs; então uma possível consequência prejudicial de um uso de uma inovação, cuja probabilidade de ocorrência não pode ser estimada, não contará como um risco, mas como uma "incerteza". Não faço esta distinção. 
alcance da pesquisa-SD, e não podem ser investigados sob SDs em ARPs, mesmo que as ARPs, ditas relevantes pelas comissões, sejam bem conduzidas e exaustivas. ${ }^{6}$ Mais geralmente, para as perspectivas de valor que motivam a pesquisa em P-MS, as ARPs, uma vez que são realizadas em contextos restritivos, não tratam

(a) de muitas das condições presentes nos contextos do mundo da vida nos quais as inovações serão efetivamente introduzidas;

(b) das consequências não intencionais e dos riscos que requeiram as SCs para a sua investigação; e

(c) de comparações com os benefícios/riscos de práticas alternativas (por exemplo, a agroecologia) que sejam informadas por conhecimento obtido em pesquisa SC.

Portanto, o PLT não serve para informar adequadamente a tomada de decisões em situações nas quais se levantam questões sobre os riscos (a possibilidade) de causar dano sério, mas prevalece a ignorância ou a incerteza acerca (1) dos detalhes do dano potencial e/ou da seriedade dele, e a probabilidade de que ele viria a ocorrer e quando, e (2) de qual seja o potencial das alternativas atualmente disponíveis. O princípio de precaução (PP) serve mais adequamente nessas situações.?

O PP nunca contesta os resultados confirmados de acordo com a imparcialidade na pesquisa-SD acerca do funcionamento e da eficácia de objetos tecnocientíficos, tampouco nega o fato de que benefícios amplamente valorizados são produzidos a partir da pesquisa-SD. Além disso, concorda - quando é confirmado nas ARPs que há risco de dano sério possivelmente causado pelo uso de uma inovação - que é obrigatório adiar (e, às vezes, abandonar) sua introdução no mundo da vida, para dar tempo para conduzir mais ARPs ou desenvolver regulamentos. Para o PP, contudo, essa obrigação de tomar precaução antes de introduzir uma inovação tecnocientífica no mundo da vida surge também em outras situações e envolve não só pesquisas conduzidas nas ARPs, mas também pesquisas que usam as SCs.

Uso "risco" no seu sentido coloquial como "possível consequência prejudicial". Sobre "risco" e "incerteza", ver Jerónimo \& Garcia (2011); Jerónimo (2014).

6 Cf. Lacey (2011a) para a discussão das lacunas alegadas das ARPs em informarem as decisões das comissões no caso dos transgênicos.

7 O princípio de precaução desempenha um papel em vários acordos internacionais (por exemplo, o Protocolo de Cartagena sobre biodiversidade). Mas pode ser enganoso falar de "o" princípio de precaução, porque não há, até o momento, uma formulação única ou padrão. Muitos grupos estão de acordo sobre a obrigação de adotar uma postura de precaução a respeito do uso das inovações tecnocientíficas; mas chegar a "o" PP ainda é um trabalho em andamento. Com esta versão de PP, pretendo fazer uma contribuição em direção a uma formulação mais completa e livre dos compromissos que inevitavelmente entram nas formulações dos acordos internacionais (cf. Lacey, 2006b). 
Tegnogiêngia Gomergialmente orientada ou investigaÇão multiestratégica?

Aplica-se o PP em situações nas quais o estado atual da pesquisa científica - isto é, o conhecimento científico estabelecido (obtido de pesquisas SD e SC) e as teorias que estão sendo utilizadas em pesquisa atualmente em curso (na etapa $\mathrm{M}_{2}$ ) - é consistente com e fornece algum grau de apoio (empírico ou teórico) para a plausibilidade da hipótese de que o uso da inovação poderia ocasionar dano sério, e talvez irreversível, para as pessoas, os arranjos sociais ou a natureza; mas não torna possível emitir juízos, endossados pelos que aderem a uma variedade de perspectivas de valor, acerca do caráter, extensão, significado ou probabilidade da ocorrência das possíveis consequências eticamente importantes (riscos) da introdução da inovação. ${ }^{\mathbf{8}}$ Nessas situações e sujeito aos esclarecimentos que se seguem - o PP propõe que as intervenções devem ser feitas com o fim de evitar dano potencial ou diminuir seu impacto, de modo que essas intervenções devem levar em conta tanto a seriedade do prejuízo potencial quanto as possíveis consequências negativas das próprias intervenções (inclusive do prejuízo dos benefícios esperados da introdução da inovação); e, caso o dano potencial seja considerado suficientemente sério, as intervenções podem incluir o adiamento das decisões finais relativas a se, e sob quais condições e regulamentos, a inovação pode ser implementada.

Cabe neste ponto fazer alguns esclarecimentos (cf. Lacey, 2006b).

(1) Qualquer adiamento, feito em resposta ao PP, tem por fim realizar pesquisa planejada para expandir a gama do que poderia ser antecipado e para reduzir as incertezas prevalecentes; a pesquisa seria conduzida sob as SCs relevantes (bem como as SDs) a respeito (a) dos danos que podem ocorrer no contexto de uso atual da inovação no mundo da vida, inclusive os danos ecológicos e sociais a longo prazo, levando em conta todos os mecanismos (socioeconômicos, bem como físicos, químicos e biológicos) que poderiam ocasionar os danos, bem como as medidas reguladoras que poderiam ajudar a reduzi-los e (b) das possibilidades e riscos das abordagens e práticas alternativas.

(2) Quando, depois da deliberação informada pelo PP, uma inovação for introduzida para uso no mundo da vida, deve haver monitoramento amplo, sistemático e de longo prazo de seus efeitos, de modo a permitir que a decisão seja revista ou revertida caso sejam obtidas novas evidências de que danos são efetivamente ocasionados, ou de que a probabilidade dos

8 Sobre os “endossamentos”, ver Lacey \& Mariconda, neste número, seção 5; Lacey, 2008a; 2011b; no prelo b. Sobre a imbricação entre a determinação empírica da extensão do risco e o processo de regulamentação técnica e regulação jurídica, ver Mariconda, 2014, seção 3. 
riscos de causar danos seja maior do que a probabilidade calculada anteriormente.

(3) A avaliação da seriedade do dano potencialmente ocasionado pela inovação (e sua comparação com a do dano antecipado devido às próprias intervenções) é feita à luz dos valores contidos em $\left\{\mathrm{V}_{\text {JSDPS }}\right\}$, de modo que quanto mais sério o dano potencial, maior deve ser a probabilidade de que ele não venha a ocorrer, ou de que ele seja adequadamente regulado.

(4) Decisões sobre questões controvertidas - por exemplo, sobre (a) a hierarquia dos valores envolvidos na avaliação da seriedade dos riscos; ${ }^{9}$ (b) a investigação científica das consequências que provocam danos (e benefícios/riscos de práticas alternativas), suas prioridades e quais estratégias são prioritariamente financiadas; (c) a duração do período de adiamento da tomada das decisões finais sobre a implementação de uma inovação; e (d) a proibição de uma inovação cujo uso havia sido anteriormente permitido - devem ser feitas no curso de deliberações democráticas, nas quais participem representantes de todas as perspectivas de valor (racionalmente viáveis) sustentadas na sociedade.

Essa formulação deixa claro que o PP diz respeito ao empreendimento da pesquisa científica, além da tomada de decisões sobre as inovações da TC e o processo de regulamentação dessas inovações (que envolve propostas legais e responsabilidades jurídicas, das quais não tratarei aqui). O PP tem implicações, por exemplo, a respeito das estratégias que devem ser adotadas nas pesquisas exigidas para fornecer o input científico relevante para as deliberações acerca da legitimidade, e a respeito das prioridades das instituições e organizações científicas. Além disso, seria difícil sustentar o PP e não aceitar que é eticamente irresponsável participar no tipo de pesquisa dirigido para as inovações tecnocientíficas - por exemplo, na biotecnologia, nanotecnologia, geoengenharia, biologia sintética, novas tecnologias genéticas, biocombustíveis - a menos que sejam conduzidas pesquisas dos dois seguintes tipos:

(1) pesquisas rigorosas e sistemáticas sobre os riscos e incertezas ecológicos e sociais, inclusive a longo prazo, da implementação das inovações no mundo da vida (apoiadas por recursos que, se não forem comparáveis àque-

9 Por exemplo, na discussão a respeito de quais devem ser as políticas a adotar em resposta ao aquecimento global, parece difícil reconciliar justiça social e sustentabilidade. Ou, como comparar a seriedade ética da perda de lucros (pelas corporações) com a da perda de saúde pelos agricultores e suas comunidades, ou ainda, o enfraquecimento do direito à segurança alimentar das pessoas em regiões empobrecidas? 
Tegnogiêngia Gomergialmente orientada ou investigaÇÃo multiestratégica?

les disponíveis para a pesquisa que deu origem às inovações, sejam pelo menos suficientes para obter conhecimento para dar maior credibilidade às deliberações), levando em conta as condições socioeconômicas das implementações planejadas e as condições atuais de seu uso;

(2) pesquisas pertinentes para a avaliação dos benefícios dos usos das inovações em comparação com os das alternativas possíveis (que talvez não sejam produtos da TC, mas informadas pelos resultados da pesquisa-SC).

A utilização perspicaz do PP depende da obtenção de resultados da pesquisa-SC que permitam informar práticas que incorporam $\left\{\mathrm{V}_{\text {JSDPS }}\right\}$, e requer que se leve em conta essas alternativas nas deliberações das comissões reguladoras.

Há várias instituições (frequentemente apoiadas por ONGs) que se engajam nesse tipo de pesquisa. ${ }^{10}$ De acordo com meu argumento, essas pesquisas devem tornar-se parte do cotidiano das instituições científicas do mainstream. Além disso, quando se considera a introdução de uma inovação, o PP conduz a levantar a questão acerca do espaço das alternativas: qual seria o alcance das alternativas que poderiam estar disponíveis, se pesquisa apropriada tivesse sido conduzida? Em decorrência, qual das alternativas (considerando todas as coisas) seria a melhor alternativa? Ou, mais exatamente, tomando em conta que "a melhor" pode ser entendida diferentemente do ponto de vista de diferentes locações e perspectivas de valor, qual é o conjunto das alternativas, variadas e apropriadamente combinadas, que constituiria a melhor abordagem a adotar? ${ }^{\mathbf{1 1}}$

PP reforça o lado crítico da P-MS. Na medida em que estimula a questão sobre o espaço das alternativas, serve para tornar o lado crítico inseparável do programa positivo da P-MS. Então, em paralelo ao esquema expandido da TC, [2A], temos este outro esquema para P-MS:

[2 $\mathbf{B}] \mathrm{P}-\mathrm{MS}=[\mathrm{SDs}+\mathrm{SCs}]\{$ papel para muitas perspectivas de valor $\}+\mathrm{A}\{$ do pluralismo estratégico $\}+\mathrm{N}$ \{inclusividade e equitatividade $\}+\mathrm{I}+\mathrm{PP}+\ldots$.

10 O Grupo ETC - Erosão, Tecnologia, Concentração -, ONG baseada no Canadá, é um exemplo bem conhecido. O ETC monitora (patrocina ou coordena) pesquisas sobre os riscos de grande variedade de inovações tecnocientíficas já mencionadas no contexto de advogar o uso do PP. 〈http://www.etcgroup.org/〉.

11 Essa questão generaliza a questão do espaço das alternativas agrícolas, elaborada em Lacey, 2008b; 2011a; no prelo a. 


\section{ComentáRios FinAis}

Argumentei que podemos atualmente identificar duas abordagens que visam dar continuidade às realizações positivas da tradição científica moderna: a tecnociência comercialmente orientada e a pesquisa multiestratégica. Sem dúvida, a TC e a P-MS, tal como representadas respectivamente em [2A] e [2B], são tipos ideais, e nas práticas conduzidas nas instituições científicas vigentes podemos achar, ao lado da TC predominante, vários híbridos das duas abordagens. Por exemplo, tentativas de combinar a TC (ou talvez a tecnociência separada da sua contribuição a $\left.\left\{V_{\text {C\&M }}\right\}\right)$ e a adoção do PP (em uma versão menos exigente do que a exposta aqui). Neste artigo, não exploro os possíveis híbridos estáveis e sustentáveis (se houver), mas, a partir de M-CV, traço em linhas gerais um fundamento filosófico e metodológico para a P-MS. A relevância social do argumento depende da promessa de realização mais ampla do programa positivo da P-MS, bem como da força de sua crítica à TC.

A crítica à TC é importante; mas a crítica, desacompanhada de uma alternativa positiva e da esperança de seu desenvolvimento, tem pequeno significado no mundo da vida. A pesquisa científica não pode ser empreendida sem a disponibilidade de certas condições sociais e econômicas, e normalmente a disponibilidade delas é controlada pelas instituições científicas. Porém, dado que as instituições científicas do mainstream estão fortemente comprometidas com a TC, não é provável que elas mesmas tornem disponíveis condições suficientes para a expansão da prática da P-MS. Nessas instituições, há relativamente pouco espaço disponível para (por exemplo) o ensino, o treino e a pesquisa da agroecologia - e poucas posições, cursos e bolsas para a pesquisa conduzida sob SCs. Portanto, as instituições científicas (com algumas exceções notáveis) não proporcionam as condições necessárias para formar grupos de trabalho necessários para desenvolver o programa positivo da P-MS. E, na ausência dessas condições, não se pode testar se a P-MS, conduzida nas áreas não tratadas adequadamente pela pesquisa da TC, poderia vir a desenvolver-se com a profundidade e fecundidade que permitiriam a comparação com a pesquisa desenvolvida pela TC.

À primeira vista, este estado de coisas parece sugerir que, realisticamente, a TC é a única opção viável; e que à P-MS faltam as condições institucionais exigidas para o seu crescimento maduro, de modo que ela assim permanecerá, na melhor das hipóteses, um empreendimento marginal ou simplesmente uma possibilidade lógica ou conceptual. Mas, como vimos na seção 3.3, é um erro identificar a ciência com as suas formas institucionalizadas, e o potencial de seu desenvolvimento com o de sua trajetória nas instituições atuais. A tensão com os ideais tradicionais poderia desencadear o início de mudanças. As instituições atuais do mainstream são dominadas pela TC, tendo enfraquecido esses ideais. Em contraste, a P-MS responde aos ideais, mas carece 
das condições institucionais adequadas. Segue-se que o crescimento amplo da P-MS dependeria da reinstitucionalização da ciência de maneira a possibilitar a reabilitação dos ideais da neutralidade e abrangência (e autonomia) (cf. Lacey, 2008a; 2014a). Enquanto isso, os praticantes da P-MS procurarão qualquer espaço hospitaleiro que possa ser achado nas instituições do mainstream (por exemplo, as universidades) e nas ONGs, nos programas governamentais e em organizações internacionais abertas à cooperação. A motivação deles deriva simultaneamente de várias fontes:

(1) da sustentação de $\left\{\mathrm{V}_{\text {JSDPS }}\right\}$ (ou de outros valores, por exemplo, os feministas ou ambientalistas, que contestam os valores de $\left\{\mathrm{V}_{\mathrm{PT}}\right\}$ e $\left.\left\{\mathrm{V}_{\mathrm{C \& M}}\right\}\right)$;

(2) dos ideais tradicionais da ciência e, assim, a retificação do enfraquecimento deles na TC;

(3) do desejo de expandir a gama dos sucessos científicos e práticas já alcançados e de participar de maneiras construtivas com as pessoas, comunidades e movimentos cujas praticas dão origem a, e utilizam, o conhecimento obtido a partir da pesquisa conduzida na P-MS e, assim, fortalecer a incorporação de $\left\{\mathrm{V}_{\text {JSDPS }}\right\}$ no mundo da vida atual (cf. Lacey, 2008b; 2012,b); (4) do compromisso de tornar visíveis os riscos e danos causados pelo uso de muitas inovações tecnocientíficas, de propor uma abordagem alternativa "melhor" e influenciar as autoridades reguladoras na direção do uso sistemático do PP.

No contexto de M-CV, podemos ver claramente que essa mistura de motivações científicas e valorativas (políticas) envolve o uso dos valores de maneira legítima nas etapas das atividades científicas relevantes, e não o emprego de valores éticos/sociais/ políticos ao lado dos valores cognitivos na etapa $\mathrm{M}_{3}$. A motivação para a participação na P-MS, como na TC, envolve o compromisso com valores éticos/sociais; dessemelhante da TC, envolve também forte compromisso com os ideais promulgados por toda a tradição científica. Não há nenhuma razão "científica”, ou baseada em considerações democráticas, para não abrir mais espaços nas instituições científicas para o desenvolvimento da pesquisa e do ensino da P-MS.ศ

Agradecimentos. O autor agradece o financiamento da Fapesp recebido pelo Projeto Temático 2011/51614-3: "Gênese e significado da tecnociência: das relações entre ciência, tecnologia e sociedade", do qual este artigo é um dos resultados. 


\title{
Commercially oriented technoscience or multi-strategy research?
}

\begin{abstract}
The model of the interactions between scientific activities and values (M-CV) provides tools to criticize the scientific activities that are currently predominant in scientific institutions, and to identify some alternative possibilities for research that are not receiving due recognition in them. Most importantly, M-CV helps us to identify a deep incoherence in the common self-interpretation of the modern scientific tradition, and also to recognize that there are available two competing coherent interpretations 'commercially oriented technoscience' and 'multi-strategy research' - that maintain continuity with the great cognitive successes of modern science.
\end{abstract}

KeYwords $\bullet$ Commercially oriented technoscience. Multi-strategy research.

Decontextualizing strategies. Impartiality. Comprehensiveness. Neutrality. Technological progress.

Social justice. Sustainability.

\section{REFERÊNGIAS BIBLIOGRÁFIGAS}

Domingues, I. O sistema de comunicação da ciência e o taylorismo acadêmico: questionamentos e alternativas. Estudos Avançados, 28, 82, p. 225-50, 2014.

Garcia, S. G. A tecnologia social como alternativa para a reorientação da economia. Estudos Avançados, 28,82, p. $25^{1-} 75,2014$.

Jerónimo, H. M. Riscophrenia and "animal spirits": clarifying the notions of risk and uncertainty in environmental problems. Scientiae Studia, 12, special issue, p. 57-74, 2014.

Jerónimo, H. M. \& Garcia, J. L. Risks, alternative knowledge strategies and democratic legitimacy: the conflict over co-incineration of hazardous industrial waste in Portugal. Journal of Risk Research, 14, 8, p. 951-67, 2011.

Koide, K.; Ferreira, M. T. \& Marini, M. Arqueologia e a crítica feminista da ciência. Entrevista com Alison Wylie. Scientiae Studia, 12, 3, p. 549-90, 2014.

LAGEY, H. Is science value free? Values and scientific understanding. London: Routledge, 1999. A controvérsia sobre os transgênicos: questões científicas e éticas. São Paulo: Idéias e Letras, 2006a. O princípio de precaução e a autonomia da ciência. Scientia Studia, 4, 3, p. 373-92, 2006b. . Aspectos cognitivos e sociais das práticas científicas. Scientiae Studia , 6, 1, p. 83-96, 2008a. Ciência, respeito à natureza e bem-estar humano. Scientiae Studia, 6, 3, p. 297-327, 2008b.

. The interplay of scientific activity, worldviews and value outlooks. Science \& Education, 18, 6- 7 , p. $839-60,2009$. 
Tegnogiêngia Gomergialmente orientada ou investigaÇão multiestratégica?

Lacey, H. Valores e atividade científica 2. São Paulo: Associação Filosófica Scientiae Studia/Editora 34, 2010.

Prefácio. In: TAIT, M. M. Tecnociência e cientistas: cientificismo e controvérsias na política de biossegurança brasileira. São Paulo: Editora Annablume, 2011a. p. 13-29.

. A imparcialidade e as responsabilidades dos cientistas. Scientiae Studia, 9, 3, p. 487-500, 2011 b.

Reflections on science and technoscience. Scientiae Studia, 10, special issue, p. 103-28, $2012 \mathrm{.}$.

Las diversas culturas y la práctica de la ciencia. In: Molina, F. T. \& Giuliano, G. (Org.). Culturas científicas y alternativas tecnológicas. Buenos Aires: Ministerio de Ciencia, Tecnología e Innovación Productiva, 2012b. p. 133-69.

Rehabilitating neutrality. Philosophical Studies, 162, p. 77-83, 2013.

Science, respect for nature, and human well-being: democratic values and the responsibilities of scientists today. Foundations of Science. Publicado on-line 21 out. 2014. DOI: 10.1007/s10699-014$9376-9,2014$ a.

. Scientific research, technological innovation and the agenda of social justice, democratic participation and sustainability. Scientiae Studia, 12, special issue, p. 37-55, 2014b.

. O modelo de Hugh Lacey para a análise da relação entre valores e atividade científica. Entrevista de Hugh Lacey por Mauro Bellesa, publicado 12 mar. 2014, Instituto de Estudos Avançados, Universidade de São Paulo. Disponível em: <http://www.iea.usp.br/noticias/entrevista-hugh-lacey>. 2014c.

. A agroecologia: uma ilustração da fecundidade da pesquisa multiestratégica. Estudos Avançados, 29, 83, 2015. No prelo a.

"Holding" and "endorsing" claims in the course of scientific activities. Studies in History and Philosophy of Science. No prelo b.

Lacey, H. \& Mariconda, P. R. O modelo das interações entre os valores e as atividades científicas. Scientiae Studia, 12, 4, p. 64,3-68, 2014.

Lechopier, N. Quatro tensões na saúde pública. Estudos Avançados, 29, 83, 2015. No prelo.

Longino, H. E. Studying human behavior: how scientists investigate aggression and sexuality. Chicago: The University of Chicago Press, 2013.

MARIconda, P. R. Technological risks, transgenic agriculture and alternatives. Scientiae Studia, 12, special issue, p. 75-104, 2014.

Molina, F. T. \& Giuliano, G. (Org.). Culturas científicas yalternativas tecnológicas. Buenos Aires: Ministerio de Ciencia, Tecnología e Innovación Productiva, 2012.

NodAri, R. O. \& Guerra, M. P. A agroecologia: suas estratégias de pesquisa e sua relação dialética com os valores da sustentabilidade, justiça social e bem-estar humano. Estudos Avançados, 29, 83, 2015. No prelo.

Oliveira, M. B. On the commodification of science: the programmatic dimension. Science \& Education, 22, 10, p. 24,63-83, 2013.

. A dádiva como princípio organizador da ciência. Estudos Avançados, 28, 82, p. 201-23, 2014.

Ramos, M. De C. Aideia de racionalidade subjacente ao modelo das interações entre a ciência e os valores: florescimento cognitivo, humano e da vida. Scientiae Studia, 12, 4, p. 711-26, 2014.

Silva, A. T. R. DA. A conservação da biodiversidade entre os saberes da tradição e a ciência. Estudos Avançados, 29, 83, 2015. No prelo.

TaIt, M. M. Tecnociência e cientistas: cientificismo e controvérsias na política de biossegurança brasileira. São Paulo: Editora Annablume, 2011.

WyLIE, A. Thinking from things: essays in the philosophy of archeology. Berkeley: University of California Press, 2002.

. Arqueologia e a crítica feminista da ciência. In: Koide, K.; Ferreira, M. T. \& Marini, M. Entrevista com Alison Wylie. Scientiae Studia, 12, 3, p. 549-90, 2014. 